is described by N. F. Spurr, whilo not tho least valuable article is one by Dr. A. L. Knutson, of the United States Public Health Service, who suggests ways in which the effectiveness of visual material may be evaluated.

\section{Ultrasonic Testing of Concrete}

THE Road Research Laboratory deals with the non-destructive testing of concrete in its Technical Paper No. 34, entitled "Testing Concrete by an Ultrasonic Pulse Technique", by Dr. R. Jones and E. N. Gatfield (pp. $48+2$ plates. London: H.M.S.O., $1955 ; 2 s .6 d$. net). Until recently, the only way in which the physical characteristics of concrete and the changes brought about by ageing and other causes could be determined was by tests to destruction carried out on specially prepared specimens. These tests, though useful, are not entirely satisfactory, and a method of measuring changes in the quality of concrete in situ by transmitting an ultrasonic pulse through concrete has been extensively investigated and developed at the Laboratory. The ultrasonic equipment described consists of two piezoelectric transducers placed on opposite faces of the concrete under test, and the pulses are timed electrically as they pass from one transducer to the other through the concrete. The time of transmission indicates the characteristics of the concrete and the presence of internal cracks. Any deterioration due to weakness or poor compaction can be detected. Examples are given of the practical applications of the method. The ultrasonic technique can also be used for testing road surfaces ; this involves the use of reflexion, the sound pulses being reflected back by the lower surface of the concrete. The difficulty here, however, is that the method is only satisfactory when the underside of the concrete is relatively smooth. In practice, transducers having natural frequencies of 50-200 kc./s. are used because of the upper limit to the froquency imposed by the attenuation of the concrete. The repetition frequency of the pulses is 50/sec., and the accuracy of measurement of the time of propagation of a pulse of longitudinal vibrations between the two transducers is of the order of $\frac{1}{2}$ per cent for concrete. Full details of the apparatus used and of the experimental technique are given in an appendix. Brief reference is made also to applications of the technique to materials other than concrete, for example, soil-cement, rocks, ceramics and wood.

\section{Catalogues of the Exhibits on Heat at the Science Museum, London}

Two well-produced illustrated handbooks have been compiled by J. A. Chaldecott, of the Science Museum, London, giving detailed descriptions of the exhibits in the collection of heat and thermal instruments at the Museum. The exhibits are arranged in a number of groups, each dealing with one aspect of the subject, and these groups are further divided into sub-groups within which the exhibits are arranged so far as possible in chronological order. The first handbook, "Heat and Cold" (pp. $64+6$ plates. London : H.M.S.O., 1954 ; 3s. net), covers thermal expansion, calorimetry, change of state and critical state, heat and heat transfer, refrigeration and low temperatures, and altogether 166 individual exhibits are listed. In addition, details are given of nine portraits of distinguished workers in the field of heat. The other handbook, "Temperature Measurement and Control" (pp. 65 +4 plates. 1955; 3s. 6d. net), is limited in content to the various types of thermo. meters, pyrometers, thermostats and temperature recorders, and 153 exhibits are listed. A reference list of thermometers and temperature-recording instruments kept in the meteorology collection of the Museum is appended for completion. In accordance with the 1948 recommendations of the Ninth General Conference on Weights and Measures, 'Celsius' is used for the temperature scale previously known as 'Centigrade'. In both handbooks the catalogue entries consist of the substance of the descriptive labels attached to the various exhibits in the Museum. The details given are most informative, and should be of considerable value and interest to physicists and to those concerned with the history of science. Though modern apparatus is by no means excluded, the emphasis is naturally on the original and earliest forms of thermal instruments. The descriptions of these in most of the text-books is now often so inadequate or incorrect that authors and students would be well advised to use the handbooks, together with a visit to the Museum, for details of particular instruments. For the more serious student, the handbook also provides the reference to the article in which the apparatus or method was originally described or to the maker or designer of a particular item. Photographs of the exhibits and lantern slides may be purchased, and the latter can also be borrowed.

\section{Energy Expenditure in Man: Symposium in London}

THE Nutrition Society is arranging a symposium on "Energy Expenditure in Man", under the chairmanship of Prof. R. C. Garry, to be held at the National Institute for Medical Research, London, N.W.7, on October 15. Papers will be read on the following topies: the development of experimental methods for determining the energy expenditure of man (Prof. C. G. Douglas, Oxford) ; modern techniques for measuring energy expenditure (Mr. H. S. Wolff, London); the value of energy expenditure measurements in nutritional studies (Dr. O. G. Edholm, London) ; daily energy expenditure by man (Dr. R. Passmore, Edinburgh); energy expenditure and age (Dr. J. V. G. A. Durnin, Glasgow); energy expenditure in athletic activities (Mr. H. R. Noltie, Leeds). Further information can be obtained from the honorary programmes secretary of the Society, Dr. R. J. L. Allen, c/o Beecham Foods, Ltd., Brentford, Middlesex.

\section{The Story of Pharmacy: Exhibition in London}

AN exhibition on "The Story of Pharmacy" has been set up by the Welleome Historical Medical Museum at the Wellcome Building, Euston Road, London, N.W.1, to coincide with the Sixteenth General Assembly of the International Pharmaceutical Federation, which is meeting in London during September 19-23. The exhibition will be opened by the president of the Federation, Sir Hugh Linstead, on September 19, following tho presidential address with which he will open the Assembly. All the objects to be shown at the exhibition have been solected from the collections at the Wellcome Museum and cover the history of pharmacy and related subjects from the earliest times to the advent of antibiotics. The exhibition is sub-divided into the following periods : prehistory, Assyria, Babylonia and Ancient Egypt ; Græco-Roman period; the medieval world; the sixteenth century; the seventeenth century ; the eighteenth century; and the nineteenth 